Research Article

\title{
Experimental Analysis of Pretensioned CLT-Glulam T-Section Beams
}

\section{J. Estévez-Cimadevila $(\mathbb{D}$, F. Suárez-Riestra $(\mathbb{D}$, D. Otero-Chans $(\mathbb{D})$, and E. Martín-Gutiérrez}

Department of Construction and Architectural, Civil and Aeronautical Structures, University of A Coruña, Campus de A Zapateira, 15071 A Coruña, Spain

Correspondence should be addressed to J. Estévez-Cimadevila; javier@udc.es

Received 4 October 2017; Accepted 5 December 2017; Published 4 March 2018

Academic Editor: Robert Cerný

Copyright (C) 2018 J. Estévez-Cimadevila et al. This is an open access article distributed under the Creative Commons Attribution License, which permits unrestricted use, distribution, and reproduction in any medium, provided the original work is properly cited.

\begin{abstract}
The bending behavior of T-section beams composed of a glulam web and an upper cross-laminated timber flange was studied. The influence of two fundamental factors on the bending strength and stiffness was considered: the wood species used for the webs and pretensioning with unbonded tendons. Sixteen specimens with a $9 \mathrm{~m}$ span were tested until failure: eight of them were nontensioned (4 Picea abies webs and 4 Quercus robur webs) and the other eight were pretensioned using threaded bars with $20 \mathrm{~mm}$ diameter anchored in plates fixed at the ends of the specimens (4 Picea abies webs and 4 Quercus robur webs). Pretensioning with unbonded tendons showed a clear improvement in the load capacity of the specimens with Picea abies webs, while the difference was not significant for the specimens with Quercus robur webs. Considering deflection, pretensioning gave the advantage of an initial precamber but also generated slight variations in the stiffness as a result of increasing the portion of the section that was in compression. The variation in the stiffness depended on the relation between the compressive and tensile moduli of elasticity parallel to the grain, and its influence on the deflection was analyzed using a finite element method.
\end{abstract}

\section{Introduction}

Pretensioning techniques are widely used for beams and slabs in concrete structures due to their ability to efficiently compensate for the reduced tensile strength of concrete through precompression. The improvement in strength achieved by pretensioning enables the use of thinner sections and provides an efficient solution for controlling material splitting and avoiding excessive deflections. For materials that have a tensile strength similar to or higher than their compressive strength, such as timber or steel, pretensioning offers significantly reduced advantages. Moreover, timber has problems with its long-term behavior; its inherent creep deflection can reduce the pretensioning effects over time, decreasing its capabilities. Therefore, the pretensioning technique is rarely used for timber.

Defect-free timber has a higher tensile strength than compressive strength. However, the inherent defects (cracks, knots, grain deviations, etc.) that are present in structural timber reduce its tensile strength. Furthermore, typical bending failure is reached instantaneously after a brittle fracture is caused by tension in the fibers. This phenomenon has motivated research on different reinforcement solutions to improve the bending behavior of timber.

The reinforcement systems that have been used can be divided in two basic typologies: passive and active reinforcements. Passive reinforcement is made of metallic elements [1-3] or fiber-reinforced polymers (FRPs) [3-13] that are glued to the timber with structural adhesives. Active reinforcement can be made with unbonded tendons or with bonded tendons that are glued to the timber with adhesives. Active reinforcement has been used to both reinforce frame connections $[14,15]$ and improve the behavior of beams [16-25].

Some authors [20,24] have studied the loss of prestressing force for LVL and glulam beams prestressed using unbonded tendons. They found a reduction in prestress from $1.4 \%$ to $10 \%$ for beams loaded parallel to the grain exposed to controlled and uncontrolled environmental conditions. They 
TABLE 1

\begin{tabular}{lcc}
\hline Bending strength & $f_{m, k}$ & $33 \mathrm{MPa}$ \\
Tensile strength parallel to the grain & $f_{t, 0, k}$ & $23 \mathrm{MPa}$ \\
Tensile strength perpendicular to the grain & $f_{t, 90, k}$ & $0.6 \mathrm{MPa}$ \\
Compressive strength parallel to the grain & $f_{c, 0, k}$ & $45 \mathrm{MPa}$ \\
Compressive strength perpendicular to the grain & $f_{c, 90, k}$ & $8 \mathrm{MPa}$ \\
Shear strength & $f_{v, k}$ & $4 \mathrm{MPa}$ \\
Modulus of elasticity parallel to the grain & $E_{0, \text { mean }}$ & $14,400 \mathrm{MPa}$ \\
Modulus of elasticity parallel to the grain & $E_{0,05}$ & $12,000 \mathrm{MPa}$ \\
Modulus of elasticity perpendicular to the grain & $E_{90, \text { mean }}$ & $800 \mathrm{MPa}$ \\
Modulus of elasticity perpendicular to the grain & $E_{90,05}$ & $660 \mathrm{MPa}$ \\
& $G_{\text {mean }}$ & $850 \mathrm{MPa}$ \\
Shear modulus & $G_{0,05}$ & $700 \mathrm{MPa}$ \\
Shear modulus & $\rho_{k}$ & $690 \mathrm{~kg} / \mathrm{m}^{3}$ \\
Characteristic density & \multicolumn{3}{l}{}
\end{tabular}

concluded that controlling the relative humidity would reduce the losses. The use of bonded reinforcements could contribute to reduce the creep deformations in wood members [5].

This paper focuses on using active reinforcement with unbonded tendons. Therefore, an important reference is the experimental study conducted by McConnell et al. [26], regarding straight beams of laminated timber with a rectangular cross section. Their study analyzed the behavior of three types of reinforcements: beams with passive reinforcement of a $12 \mathrm{~mm}$ diameter steel bar, posttensioned beams with an unbonded $12 \mathrm{~mm}$ diameter steel tendon, and posttensioned beams with a bonded $12 \mathrm{~mm}$ diameter steel tendon. They concluded that posttensioning with unbonded tendons increased the bending strength by $17.6 \%$ and the stiffness by $8.1 \%$. The small effect of pretensioning on the bending stiffness coincides with the results previously obtained by Bohannan [16].

This paper analyzes the bending behavior of T-section beams formed of glulam webs and upper cross-laminated timber (CLT) flanges. This analysis aims to determine the influence of using different wood species with different mechanical properties for the webs and the effect of pretensioning with unbonded tendons on the strength and bending stiffness of beams. The inherent loss of effectiveness of prestressing in a long-term process is assumed, but it is not considered as a determinant for the purpose of this analysis, as it is carried out in conditions of instantaneous loading.

\section{Materials and Methods}

2.1. Materials. The characteristics of the materials used in the experimental study were as follows:

(i) Glulam webs made of Picea abies, with a strength class of GL28 h [27].

(ii) Glulam webs made of Quercus robur sheets LS13 [28]. The physical and mechanical properties provided by the manufacturer are in Table 1 .

(iii) The CLT flanges, CLT90S L3S [29], were $90 \mathrm{~mm}$ thick and were composed of three sheets of $30 \mathrm{~mm}$ Picea
TABLE 2

\begin{tabular}{lcc}
\hline Bending strength & $f_{m, k}$ & $24 \mathrm{MPa}$ \\
Tensile strength parallel to the grain & $f_{t, 0, k}$ & $14 \mathrm{MPa}$ \\
Compressive strength parallel to the grain & $f_{c, 0, k}$ & $22 \mathrm{MPa}$ \\
Shear strength parallel to the grain of the boards & $f_{v, k}$ & $2.5 \mathrm{MPa}$ \\
Modulus of elasticity parallel to the grain of the boards & $E_{0, \text { mean }}$ & $12,500 \mathrm{MPa}$ \\
Shear modulus parallel to the grain of the boards & $G_{\text {mean }}$ & $460 \mathrm{MPa}$ \\
& $\rho_{k}$ & $420 \mathrm{~kg} / \mathrm{m}^{3}$ \\
\hline
\end{tabular}

abies C24 [30]. The physical and mechanical properties provided by the manufacturer are in Table 2.

(iv) The connection between the webs and the flanges of the T-sections was made with $410 \times 80 \times 4 \mathrm{~mm}$ perforated plates in S235 hot-dip galvanized finish steel. The circular drills of the plates had a diameter of $10 \mathrm{~mm}$ spaced at $5 \mathrm{~mm}$. The plates were glued to the wooden specimens with a 2 -component polyurethane adhesive.

(v) The pretensioning of the specimens was conducted using threaded bars of $\mathrm{Y} 1100 \mathrm{H}$ [31] steel with a $20 \mathrm{~mm}$ diameter, an elastic limit of $f_{p k}=900 \mathrm{~N} / \mathrm{mm}^{2}$, and a tensile strength of $f_{p \max , k}=1100 \mathrm{~N} / \mathrm{mm}^{2}$.

\subsection{Test Specimens}

2.2.1. Preliminary Tests. Two series of nondestructive tests were conducted. The aim of the first test series was to determine the global bending modulus of elasticity $\left(E_{m, g}\right)$ of the timber used. The following specimens were tested:

(i) 4 Picea abies glulam webs with a cross section of $160 \times 210 \mathrm{~mm}$

(ii) 4 Quercus robur glulam webs with a cross section of $160 \times 210 \mathrm{~mm}$

(iii) 4 CLT planks with a cross section of $600 \times 90 \mathrm{~mm}$

Four-point bending tests were conducted with a span of $9 \mathrm{~m}$ between the supports. The tested specimens were used later to form the T-sections without pretensioning, as described in Section 2.2.2.

The purpose of the second preliminary test series was to determine the compressive elastic modulus of the webs parallel to the grain $\left(E_{c, 0}\right)$. The following specimens, which were obtained from the samples previously tested for bending, were tested under centered compression:

(i) 4 Picea abies glulam specimens of $55 \times 55 \times 330 \mathrm{~mm}$

(ii) 4 Quercus robur glulam specimens of $55 \times 5 \times 330 \mathrm{~mm}$

2.2.2. Tests of the T-Section Specimens. The following characteristics of the T-sections were tested.

(1) T-Sections without Pretensioning. Eight specimens were formed using a glulam web (4 Picea abies specimens and 4 Quercus robur specimens) and upper CLT flanges (Figure 1(a)). The total length of the specimen was $9160 \mathrm{~mm}$, and 
the distance between the supports was $L=9 \mathrm{~m}$. The geometric characteristics of the T-section were as follows (Figure 1(b)): $b_{1}=600 \mathrm{~mm}, b_{2}=160 \mathrm{~mm}, h_{1}=90 \mathrm{~mm}$, $h_{2}=210 \mathrm{~mm}$, and $H=300 \mathrm{~mm}$.

The total depth $(H)$ was established by considering the slenderness of the specimen (L/30). A thickness of $h_{1}=90 \mathrm{~mm}$ was adopted for the CLT since this is the minimum commercial configuration for 3 plates. The width of the webs $\left(b_{2}\right)$ was determined by considering the restriction of the longitudinal channel in which the tendon was placed. Finally, the width of the CLT $\left(b_{1}\right)$ was selected to efficiently use the most common commercial dimensions of CLT. The adopted configuration of the T-section enables extending the results to $\pi$-shaped sections, a highly efficient typology for constructing structural floors.

The perforated plates of the connection between the web and the flanges (Figure 2) were placed as shown in Figure 3(a) for the Picea abies webs and as shown in Figure 3(b) for the Quercus robur webs.

To determine the number and distribution of the connection plates, the load capacity of the T-sections with different configurations (the pretensioned and nontensioned specimens and Picea abies and Quercus robur webs) was estimated. The load capacity was calculated considering a homogenized section obtained from the material characteristics described in Section 2 and assuming a bending failure mode.

A finite element method (FEM) analysis was performed with the obtained load values to assess the required lengths and positions of the connection plates. The adopted distribution proved to be efficient because none of the tested specimens failed at the connection between the web and flange.

(2) Pretensioned T-Sections. Eight beams were formed with a glulam web (4 Picea abies webs and 4 Quercus robur webs) and upper CLT flanges with the same characteristics as described for the nonpretensioned beams. The web cross section had a bottom groove or a cable channel of $35 \times 85 \mathrm{~mm}$, which was located $30 \mathrm{~mm}$ away from the bottom edge, where the tensioning tendon was placed (Figure 1 (b)). The vertical dimension of the groove was oversized to accommodate two tendons, which was utilized in another test series using the same specimens. To make the groove, each web was manufactured with two $80 \mathrm{~mm}$ wide specimens and the groove was machined before being glued to form the final $160 \mathrm{~mm}$ wide web. The distribution of the perforated plates that connected the web and upper flange is shown in Figure 3(b) (Picea abies) and Figure 3(c) (Quercus robur).

Table 3 shows the geometric characteristics of all the tested specimens.

2.2.3. Test Setup. The preliminary tests conducted to determine the global bending elastic modulus (Figure 4) and the compression elastic modulus (Figure 5) considered the general criteria of regulation [32] using a frame with a $600 \mathrm{kN}$

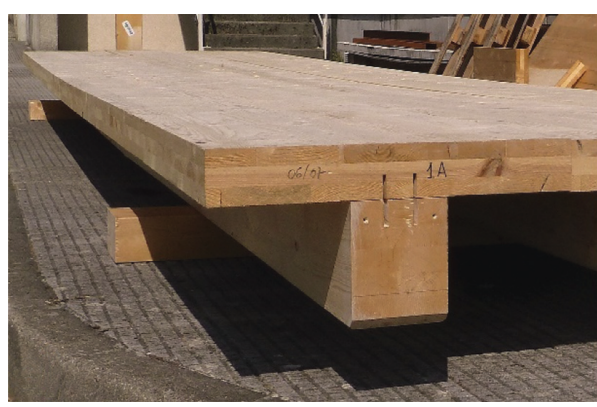

(a)

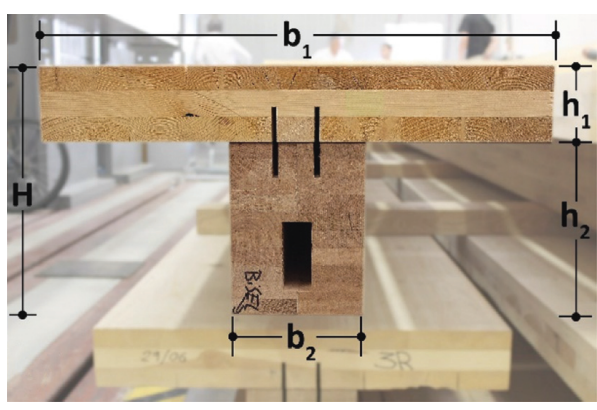

(b)

Figure 1: Picture of a solid transversal section without pretensioning (a) and a piece with a groove prepared to place the pretensioning tendon (b).

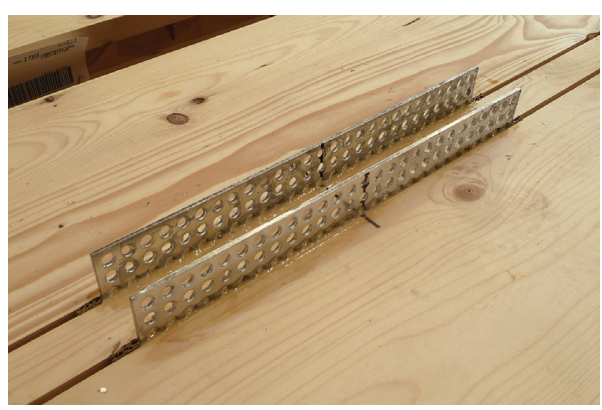

Figure 2: Discontinuous flange-to-web joint made with gluedperforated steel plates.

load cell. The bending tests were conducted using a $9 \mathrm{~m}$ span between the supports, and point loads were applied at one-third and two-thirds of the span; the midpoint displacement was measured using an extensometer with $100 \mathrm{~mm}$ of standard measurement stroke (Figure 4). The bending elastic modulus parallel to the grain $\left(E_{0 \text {,mean }}\right)$ was calculated using the following equation:

$$
E_{0, \text { mean }}=\frac{3 \cdot a \cdot L^{2}-4 \cdot a^{3}}{2 \cdot b \cdot h^{3} \cdot\left(\left(2 \cdot\left(w_{2}-w_{1}\right) /\left(F_{2}-F_{1}\right)\right)-\left(6 \cdot a / 5 \cdot G_{\text {mean }} \cdot b \cdot h\right)\right)},
$$




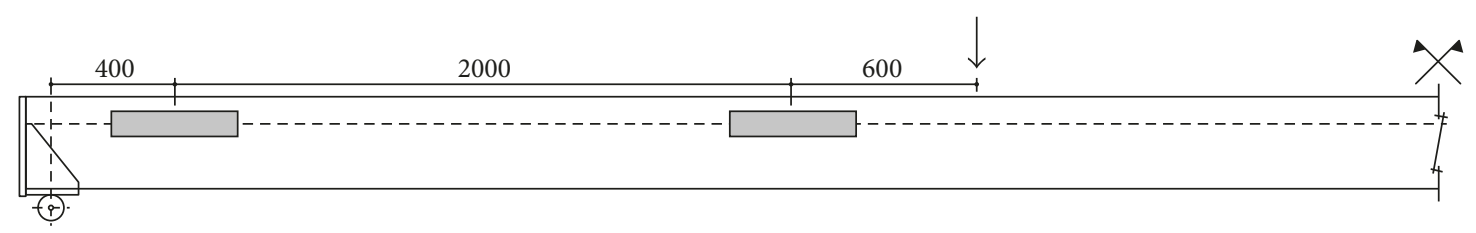

(a)

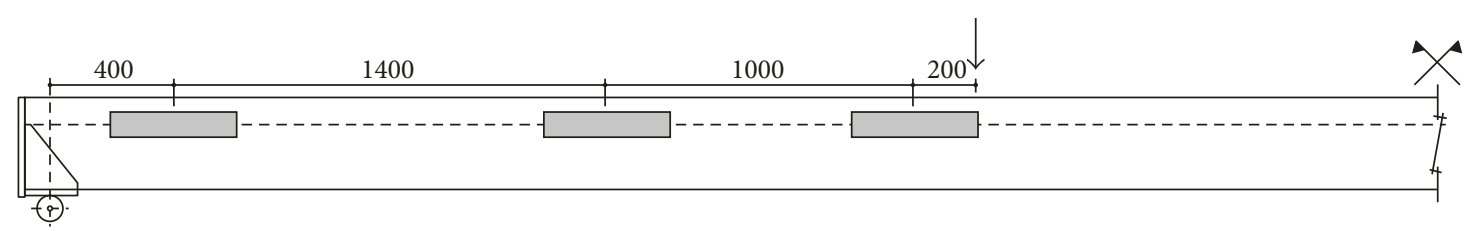

(b)

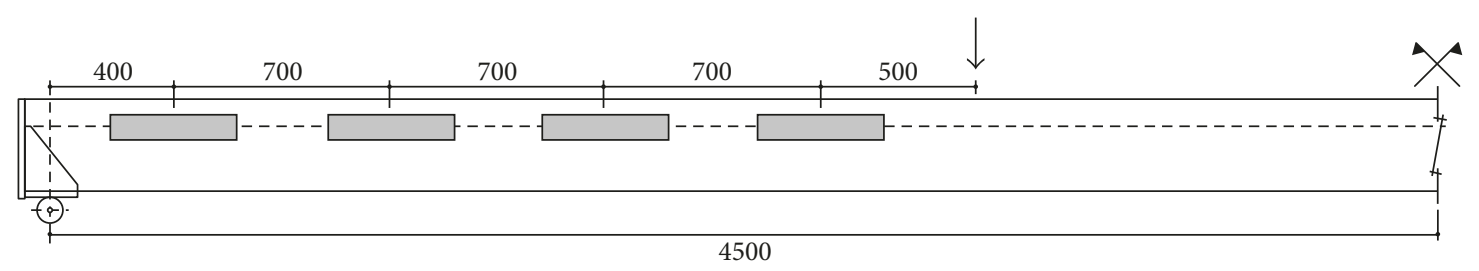

(c)

Figure 3: Dispositions of perforated steel plates adopted according to the type of piece. Nonpretensioned pieces: (a) Picea abies glulam webs and (b) Quercus robur glulam webs. Pretensioned pieces: (b) Picea abies glulam webs and (c) Quercus robur glulam webs.

TABLE 3: Geometric characteristics of the tested specimens.

\begin{tabular}{|c|c|c|c|c|c|c|c|c|c|c|}
\hline \multirow{2}{*}{ Type } & \multirow{2}{*}{ Wood } & \multirow{2}{*}{$\begin{array}{l}\text { Specimen } \\
\text { number }\end{array}$} & \multicolumn{6}{|c|}{ Specimen geometry } & \multirow{2}{*}{ Test } & \multirow{2}{*}{$\begin{array}{c}\text { Tensioning } \\
\text { tendon } \\
\Phi(\mathrm{mm})\end{array}$} \\
\hline & & & $L(\mathrm{~mm})$ & $H(\mathrm{~mm})$ & $h_{1}(\mathrm{~mm})$ & $h_{2}(\mathrm{~mm})$ & $b_{1}(\mathrm{~mm})$ & $b_{2}(\mathrm{~mm})$ & & \\
\hline $\mathrm{B} / \mathrm{PIC}-1$ to 4 & Picea abies & 4 & 9000 & - & - & 210 & - & 160 & Bending & - \\
\hline $\mathrm{B} / \mathrm{OAK}-1$ to 4 & Quercus robur & 4 & 9000 & - & - & 210 & - & 160 & Bending & - \\
\hline B/CLT- 1 to 4 & CLT & 4 & 9000 & - & 90 & - & 600 & - & Bending & - \\
\hline C/PIC- 1 to 4 & Picea abies & 4 & 330 & 55 & - & - & - & 55 & Compression & - \\
\hline C/OAK-1 to 4 & Quercus robur & 4 & 330 & 55 & - & - & - & 55 & Compression & - \\
\hline F1/PIC-1 to 4 & $\begin{array}{l}\text { T-section with } \\
\text { Picea abies web }\end{array}$ & 4 & 9000 & 300 & 90 & 210 & 600 & 160 & Bending & - \\
\hline F1/OAK-1 to 4 & $\begin{array}{c}\text { T-section with } \\
\text { Quercus robur web }\end{array}$ & 4 & 9000 & 300 & 90 & 210 & 600 & 160 & Bending & - \\
\hline F2/PIC-1 to 4 & $\begin{array}{l}\text { T-section with } \\
\text { Picea abies web }\end{array}$ & 4 & 9000 & 300 & 90 & 210 & 600 & 160 & Bending & 20 \\
\hline F2/OAK-1 to 4 & $\begin{array}{c}\text { T-section with } \\
\text { Quercus robur web }\end{array}$ & 4 & 9000 & 300 & 90 & 210 & 600 & 160 & Bending & 20 \\
\hline
\end{tabular}

where $a$ is the distance between a loading point and the nearest support, $L$ is the span of the structural element, $b$ and $h$ are the dimensions of the cross section of the beam, $F_{2}-F_{1}$ is the load increase in the straight part of the load-deflection curve, and $\omega_{2}-\omega_{1}$ is the deflection increase corresponding to load $F_{2}-F_{1}$.

The compression elastic modulus parallel to the grain $\left(E_{c, 0}\right)$ was calculated using the following equation:

$$
E_{c, 0}=\frac{L_{1} \cdot\left(F_{2}-F_{1}\right)}{A \cdot\left(w_{2}-w_{1}\right)},
$$

where $L_{1}$ is the length, 4 times the smallest dimension of the specimen; $F_{2}-F_{1}$ is the load increase in the straight part of the load-deflection curve; $A$ is the cross-sectional area of timber; and $\omega_{2}-\omega_{1}$ is the deflection increase corresponding to load $F_{2}-F_{1}$. 


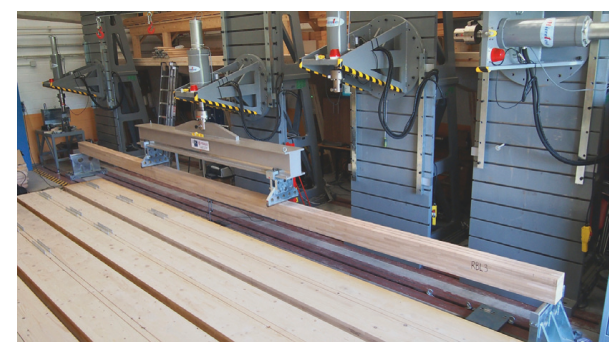

Figure 4: Bending test to determine the global bending MOE.

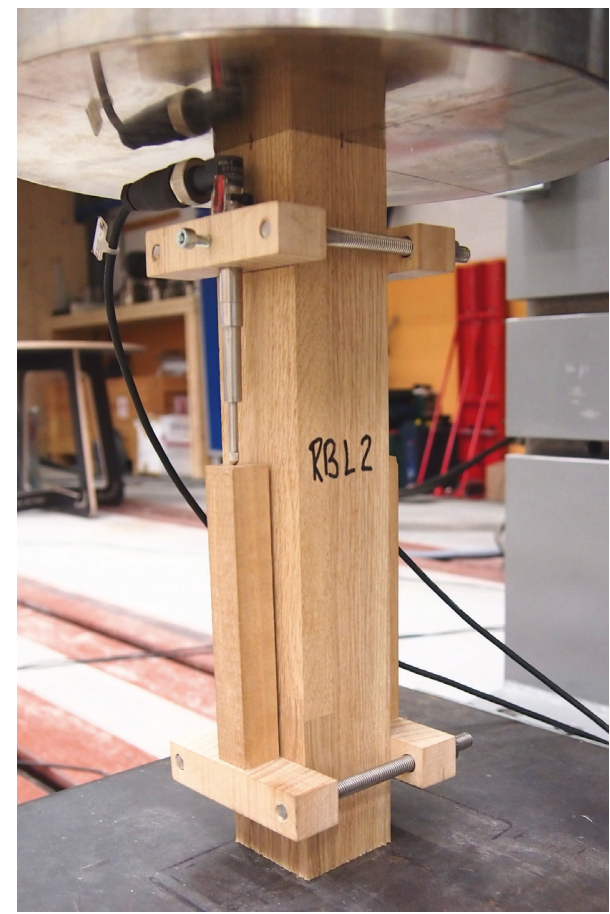

Figure 5: Test to determine the compression MOE parallel to the grain.

The T-section was tensioned using a hydraulic jack until a precamber of $18 \mathrm{~mm}(L / 500)$ was obtained. The tension force applied to reach the precamber was different for each specimen due to their different stiffnesses. The tendon was locked against the plates using a domed anchor nut [33]. The tendon was placed in the groove of the web $105 \mathrm{~mm}$ from the tendon axis to the bottom edge of the specimen (Figure 6).

\section{Results}

Table 4 shows the results that were obtained from the previous tests to determine the modulus of elasticity parallel to the grain for bending and compression. The average value of the global bending modulus of the CLT specimens from the experiments was $6 \%$ lower than the one declared by the manufacturer. Compared to the theoretical values listed in Section 2, the specimens with Picea abies and Quercus robur webs exhibited much more significant decreases in the modulus of elasticity (13.7\% for Picea abies and $17.3 \%$ for Quercus robur).

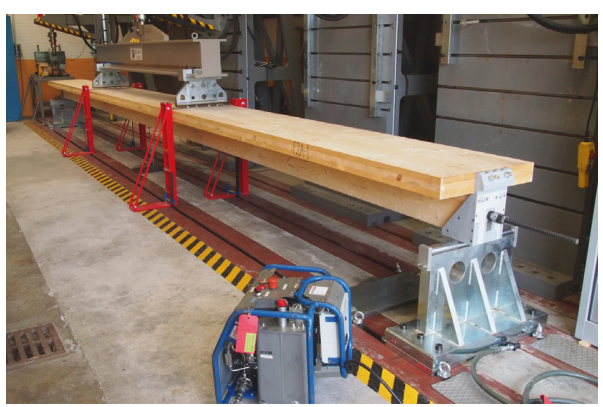

Figure 6: Test of a pretensioned T-section with Picea abies webs.

Table 5 shows the tensioning force applied to each specimen to reach the initial precamber (the maximum force at failure in the bar) and the failure load.

Table 6 presents the midpoint displacement of each T-section beam for two point loads of $14 \mathrm{kN}$; each load was applied at one-third of the span length. In terms of deflection, these point loads were equivalent to a uniformly distributed load of $7 \mathrm{kN} / \mathrm{m}^{2}$, which is a common value for public buildings $\left(G_{k}=2 \mathrm{kN} / \mathrm{m}^{2}\right.$ and $\left.Q_{k}=5 \mathrm{kN} / \mathrm{m}^{2}\right)$. The displacements listed in Table 6 do not include the deflection caused by the self-weight of the specimen because the extensometers were installed after the specimen was supported and the load had been applied. In the case of the pretensioned specimens (F2/PIC and F2/OAK), the displacement was measured after pretensioning, so such displacements were measured after some deflection had occurred; therefore, the self-weight was already considered. Thus, to determine the midpoint displacement, the $18 \mathrm{~mm}$ of initial precamber was subtracted from the corresponding value in Table 6.

Figures 7 and 8 show the load-displacement results that correspond to the bending tests of pretensioned and nontensioned T-sections with Picea abies (Figure 7) and Quercus robur webs (Figure 8 ). The minimum and maximum values obtained from the action of the two $14 \mathrm{kN}$ loads applied to one-third and two-thirds of the span length are provided. For an approximate displacement of $15 \mathrm{~mm}$, the loaddeflection curves corresponding to the pretensioned beams show a clear change in slope caused by the increase of the effective stiffness when the wood comes into contact with the steel bar. This contact occurs when the deformation generated by the beam's self-weight and the loads applied during the test offset the $18 \mathrm{~mm}$ precamber produced by the initial pretensioning force.

The failure of all T-sections, both nontensioned and pretensioned, occurred instantaneously as a result of the tension in the glulam web. In the nontensioned specimens, the predominant failure mode was typical glulam bending failure (Figure 9). In the F1/PIC-3 specimen, the failure was accelerated due to the presence of significant knots in the bottom sheet of the glulam web (Figure 10). As a result, the failure load of this specimen was the lowest of all the tested specimens (Table 5). Finger-joint failure occurred in the F1/OAK-3 specimen (Figure 11), and significant variation was not observed in the failure loads of the other tested 
TABLE 4: Modulus of elasticity parallel to the grain.

\begin{tabular}{|c|c|c|c|c|c|c|c|c|c|}
\hline \multirow{3}{*}{ Type } & \multicolumn{7}{|c|}{ Experimental test series } & \multicolumn{2}{|c|}{ Theoretical value } \\
\hline & \multicolumn{4}{|c|}{ Value for each specimen $(\mathrm{MPa})$} & \multirow{2}{*}{ Standard deviation } & \multirow{2}{*}{$\begin{array}{l}\text { Average value } \\
E_{c, 0, \text { test }}(\mathrm{MPa})\end{array}$} & \multirow{2}{*}{$\begin{array}{c}\text { Average value } \\
E_{0, \text { mean,test }}(\mathrm{MPa})\end{array}$} & \multirow{2}{*}{$\begin{array}{l}\text { Average value } \\
E_{0, \text { mean }}(\mathrm{MPa})\end{array}$} & \multirow{2}{*}{$\frac{E_{0, \text { mean,test }}}{E_{0, \text { mean }}}$} \\
\hline & 1 & 2 & 3 & 4 & & & & & \\
\hline $\mathrm{B} / \mathrm{PIC}$ & 10,880 & 11,450 & 10,510 & 10,658 & 413 & - & 10,875 & 12,600 & 0.86 \\
\hline $\mathrm{B} / \mathrm{OAK}$ & 11,641 & 11,884 & 12,222 & 11,894 & 238 & - & 11,910 & 14,400 & 0.83 \\
\hline $\mathrm{B} / \mathrm{CLT}$ & 10,913 & 11,091 & 12,833 & 12,157 & 908 & - & 11,748 & 12,500 & 0.94 \\
\hline $\mathrm{C} / \mathrm{PIC}$ & 10,208 & 11,365 & 11,115 & 8616 & 1244 & 10,326 & - & - & - \\
\hline C/OAK & 11,676 & 10,767 & 13,375 & 13,248 & 1264 & 12,267 & - & - & - \\
\hline
\end{tabular}

TABLE 5: Force in the tensioning bar and ultimate load.

\begin{tabular}{|c|c|c|c|c|c|c|c|c|c|c|c|c|}
\hline \multirow{4}{*}{ Type } & \multicolumn{6}{|c|}{ Initial prestressing force } & \multicolumn{6}{|c|}{ Total failure load } \\
\hline & \multicolumn{6}{|c|}{ Maximum force in the bar $(\mathrm{kN})$} & \multicolumn{6}{|c|}{ Sum of the two specific loads applied $(\mathrm{kN})$} \\
\hline & \multicolumn{4}{|c|}{ Specimen } & \multirow{2}{*}{$\begin{array}{l}\text { Standard } \\
\text { deviation }\end{array}$} & \multirow{2}{*}{ Average value } & \multicolumn{4}{|c|}{ Specimen } & \multirow{2}{*}{ Standard deviation } & \multirow{2}{*}{ Average value } \\
\hline & 1 & 2 & 3 & 4 & & & 1 & 2 & 3 & 4 & & \\
\hline F1/PIC & - & - & - & - & - & - & 55.25 & 64.15 & 49.48 & 61.97 & 6.67 & 57.71 \\
\hline $\mathrm{F} 2 / \mathrm{PIC}$ & $\begin{array}{l}109.20 \\
154.17\end{array}$ & $\begin{array}{c}117.03 \\
163.79\end{array}$ & $\begin{array}{l}113.16 \\
176.55\end{array}$ & $\begin{array}{l}117.89 \\
172.57\end{array}$ & $\begin{array}{l}3.99 \\
9.95\end{array}$ & $\begin{array}{l}114.32 \\
166.77\end{array}$ & 58.15 & 59.49 & 95.66 & 74.18 & 17.44 & 71.87 \\
\hline F1/OAK & - & - & - & - & - & - & 69.89 & 87.54 & 80.36 & 88.28 & 8.54 & 81.52 \\
\hline F2/OAK & $\begin{array}{l}115.54 \\
171.81\end{array}$ & $\begin{array}{c}94.06 \\
147.61\end{array}$ & $\begin{array}{l}113.29 \\
225.99\end{array}$ & $\begin{array}{l}116.00 \\
175.49\end{array}$ & $\begin{array}{l}10.51 \\
32.92\end{array}$ & $\begin{array}{l}109.72 \\
180.23\end{array}$ & 73.78 & 68.92 & 90.74 & 84.15 & 9.88 & 79.40 \\
\hline
\end{tabular}

TABle 6: Displacement at the midpoint of the span for two specific loads of $14 \mathrm{kN}$ applied at one-third and two-thirds of the span.

\begin{tabular}{|c|c|c|c|c|c|c|}
\hline \multirow{2}{*}{ Type } & \multicolumn{4}{|c|}{ Value for each specimen $(\mathrm{mm})$} & \multirow{2}{*}{ Standard deviation } & \multirow{2}{*}{ Average value $(\mathrm{mm})$} \\
\hline & 1 & 2 & 3 & 4 & & \\
\hline F1/PIC & 59.14 & 56.94 & 60.14 & 56.50 & 1.74 & 58.18 \\
\hline F2/PIC & 64.86 & 68.63 & 62.01 & 64.14 & 2.76 & 64.91 \\
\hline F1/OAK & 53.29 & 54.70 & 57.27 & 52.89 & 1.98 & 54.54 \\
\hline F2/OAK & 65.09 & 63.65 & 62.09 & 61.78 & 1.53 & 63.15 \\
\hline
\end{tabular}

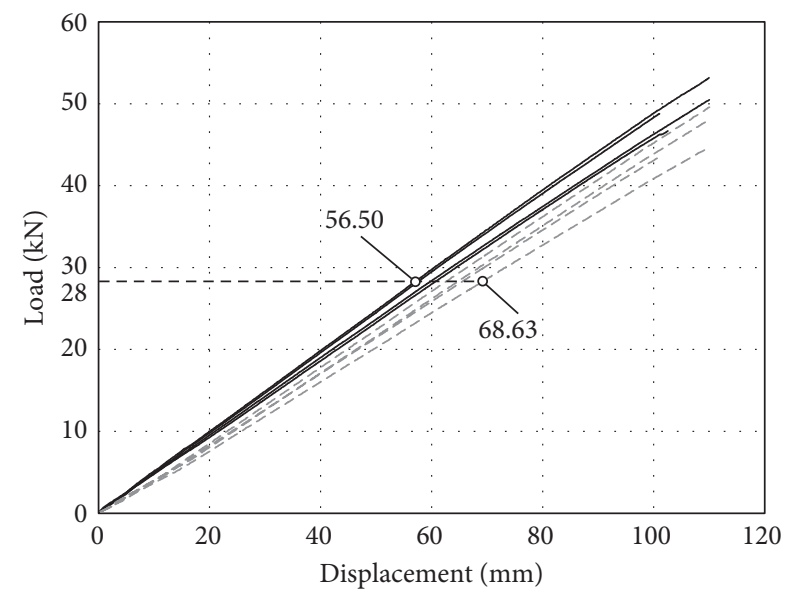

Figure 7: Load-displacement curves of T-sections with Picea abies webs: pretensioned (dashed lines) and nonpretensioned (solid lines).

specimens. In all the pretensioned specimens, with both Picea abies and Quercus robur webs, typical glulam bending failure was observed (Figure 12).

\section{Discussion}

4.1. Influence of the Type of Wood Used to Laminate the Web without Pretensioning. Using Quercus robur laminated timber webs instead of Picea abies webs in a nontensioned beam clearly improves the strength. The average failure load was $81.52 \mathrm{kN}$ for Quercus robur and $57.71 \mathrm{kN}$ for Picea abies, showing an increase of $41.2 \%$. Moreover, the lowest failure load obtained with the Quercus robur webs (F1/OAK-1, $69.89 \mathrm{kN}$ ) was $8 \%$ higher than the highest value obtained for the Picea abies webs (F1/PIC-2, $64.15 \mathrm{kN})$. Since failure of both the Picea abies and Quercus robur webs occurred because of tension in the glulam web, the larger strength of the T-section with the Quercus robur webs was clearly directly related to the enhanced mechanical properties of the hardwood species. This conclusion can be clearly verified by examining the maximum theoretical stress on the bottom fiber $\left(\sigma_{\text {bottom }}\right)$ in Table 7 , which was analytically obtained using (3) and assuming a pretensioning force $\left(N_{\text {prest }}\right)$ of zero:

$$
\sigma_{\text {bottom }}=-\frac{N_{\text {prest }}}{A}+\frac{\left(M-N_{\text {prest }} \cdot e_{\text {prest }}\right) \cdot y}{I},
$$




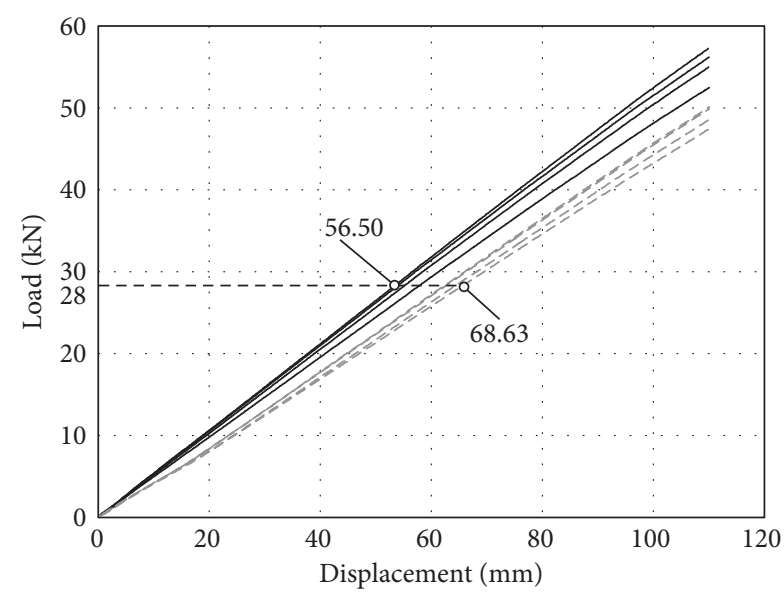

Figure 8: Load-displacement curves of T-sections with Quercus robur webs: pretensioned (dashed lines) and nonpretensioned (solid lines).

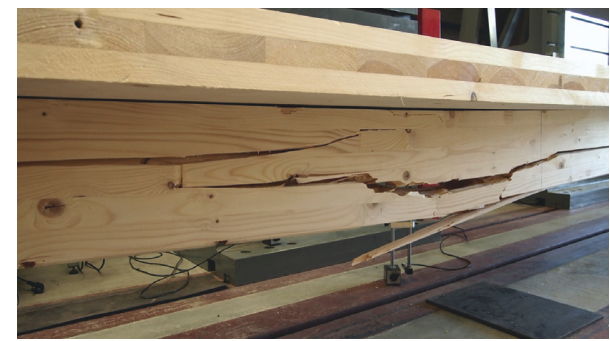

FIgURE 9: Typical bending failure in nonpretensioned T-sections corresponding to specimen F1/PIC-1.

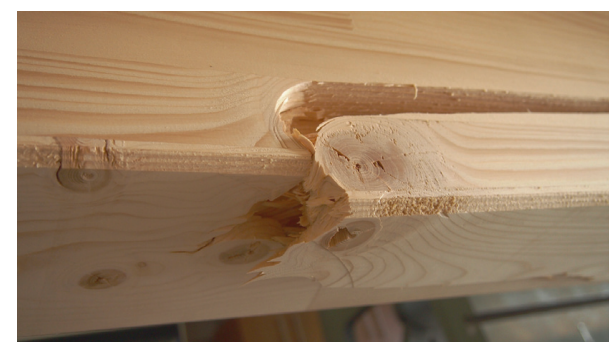

Figure 10: Failure due to knots in the specimen F1/PIC-3.

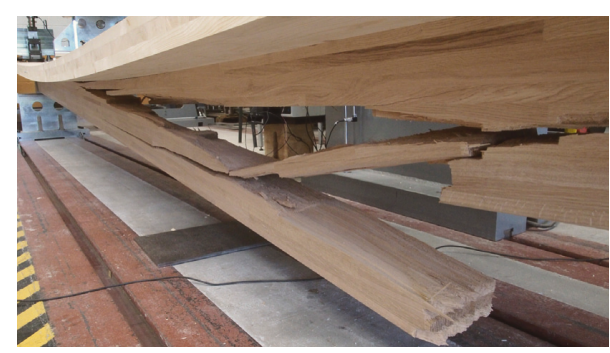

FIGURE 11: Failure close to a finger joint in the specimen F1/OAK-3.

where $A$ is the cross-sectional area of timber, $M$ is the applied moment, $e_{\text {prest }}$ is the eccentricity of the pretensioning tendon with respect to the center of mass of the cross section, $y$ is the

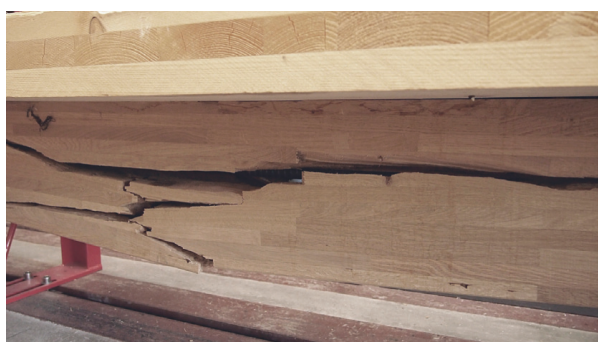

FIgURE 12: Bending failure in a pretensioned T-section corresponding to specimen F2/OAK-3.

distance to the neutral axis, and $I$ is the moment of inertia of the homogenized section.

The average global modulus of elasticity obtained from the tests on Quercus robur webs $\left(11,910 \mathrm{~N} / \mathrm{mm}^{2}\right)$ was $9.5 \%$ higher than that obtained from the tests on Picea abies webs $\left(10,875 \mathrm{~N} / \mathrm{mm}^{2}\right)$. Using the Quercus robur webs instead of Picea abies webs theoretically increased the bending stiffness (EI) of the homogenized T-section, including the upper CLT board, by $5.6 \%$. The homogenized section was calculated using the average global modulus of elasticity obtained in the tests. The theoretical increase in the bending stiffness (5.6\%) was similar than the reduction in the average midpoint displacement of the tested specimens $(58.18 \mathrm{~mm}$ for the Picea abies webs and $54.54 \mathrm{~mm}$ for the Quercus robur webs). This low increase in the bending stiffness was easily achieved by slightly increasing the depth of the Picea abies webs. In the analytical case, the increase in the stiffness provided by using the Quercus robur webs could be achieved by increasing the depth of the Picea abies webs from $210 \mathrm{~mm}$ to $215.7 \mathrm{~mm}$ (a $2.7 \%$ increase in the depth).

In conclusion, the use of laminated hardwood in the webs of a T-section provides a clear increase only in strength. However, in building structures, the dimensions of simply supported specimens with a medium or long span (the appropriate spans for the type of section analyzed) are not usually determined by strength limitations but by deformation limitations. As a result, the increase in stiffness gained from using glulam hardwood can hardly compensate for the increased cost.

4.2. Influence of Pretensioning on the Bending Strength. Simply supported specimens were pretensioned with unbonded tendons to improve their strength; by applying an eccentric tensioning force, the positive bending generated from exterior loads was reduced. The magnitude of the tensioning force must be limited to ensure that the resultant precamber does not surpass the standard values of service limit states. This limitation in the negative bending magnitude that is induced by pretensioning, together with the additional compressive stresses inherent to tensioning, eliminates the relevance of the increased strength.

Table 5 shows the failure loads of all tested specimens. The specimens with Picea abies webs reached an average failure load of $71.87 \mathrm{kN}$ in the pretensioned specimens and $57.71 \mathrm{kN}$ in the nontensioned specimens. However, this increase of 
TABLE 7: Maximum tensile stress estimated for the failure load.

\begin{tabular}{|c|c|c|c|c|c|c|}
\hline \multirow{2}{*}{ Type } & \multicolumn{4}{|c|}{ Value for each specimen (MPa) } & \multirow{2}{*}{ Standard deviation } & \multirow{2}{*}{ Average value $(\mathrm{MPa})$} \\
\hline & 1 & 2 & 3 & 4 & & \\
\hline F1/PIC & 25.75 & 29.90 & 23.06 & 28.88 & 3.11 & 26.90 \\
\hline $\mathrm{F} 2 / \mathrm{PIC}$ & 21.54 & 21.32 & 45.67 & 35.41 & 11.80 & 30.98 \\
\hline F1/OAK & 33.06 & 41.41 & 38.01 & 41.76 & 4.04 & 38.56 \\
\hline $\mathrm{F} 2 / \mathrm{OAK}$ & 28.67 & 33.43 & 44.01 & 40.81 & 6.96 & 36.73 \\
\hline
\end{tabular}

24.5\% must be considered in the context of three issues. First, the small number of tested specimens prevents the results from being conclusive. Second, the low value of the failure load $(49.48 \mathrm{kN})$ of test specimen F1/PIC-3 occurred due to the presence of knots on the bottom side accelerating the failure (Figure 10). Finally, the high value of the failure load $(95.66 \mathrm{kN})$ reached by test specimen F2/PIC-3 resulted in a standard deviation for the pretensioned specimens (17.44) that was significantly higher than that of the nontensioned specimens (6.67). The tensioning force applied to the four tested specimens is shown in Table 5. The negative bending moment produced by tensioning was calculated using the global modulus of elasticity of each specimen and the eccentricity of the tendons in relation to the center of gravity of the homogenized sections: 12.83, 13.42, 15.93, and $15.15 \mathrm{kN} \cdot \mathrm{m}$ for specimens $\mathrm{F} 2 / \mathrm{PIC}-1$ to 4 , respectively. As shown, the largest negative moments (specimens 3 and 4) corresponded to the specimens that reached a higher failure load. However, expressing the negative moment values as a percentage of the isostatic moment produced by the failure load gives the following results: $33.10 \%$, $33.84 \%, 24.97 \%$, and $30.64 \%$ for specimens F2/PIC-1 to 4 , respectively. The lowest percentage of the counterbalance moment was produced using specimen F2/PIC-3, which reached the highest failure load, and very significant differences were observed regarding the other specimens.

As a result, since the pretensioning and moment generated by the eccentric pretensioning load were very similar for the 4 specimens, the excellent strength behavior of such specimens could have been a direct consequence of the inherent variations in the mechanical properties of timber. This variation is also reflected in the theoretical tension at the moment of failure (Table 7).

In the specimens with Quercus robur webs, pretensioning did not increase the average failure load; these values were even lower than those of the nontensioned specimens ( $79.40 \mathrm{kN}$ and $81.52 \mathrm{kN}$, resp.). Table 7 compares the results in terms of the average theoretical stress at the moment of failure. The tensioning force applied to the four Quercus robur test specimens and the maximum force reached by the tendon are shown in Table 5. The negative bending moments produced by the eccentric tendon at the moment of failure were $13.88,11.89,19.16$, and $14.71 \mathrm{kN} \cdot \mathrm{m}$ for specimens F2/OAK-1 to 4, respectively. The highest value of the counterbalance moment was once again observed in the specimen that reached the highest ultimate load value. This result was also observed when the moments were expressed as a percentage of the isostatic moment at the ultimate load: $28.21 \%, 25.89 \%, 31.68 \%$, and $26.23 \%$, respectively. The obtained results reveal that the differences in the ultimate loads of the pretensioned and nontensioned specimens with Quercus robur webs were more closely related to the specific material properties than to the influence of pretensioning.

As a result, although it was not possible to reach definite conclusions, the test results indicate that the benefits of pretensioning on the bending strength of the specimens were not especially relevant. This observation was attributed to the fact that the maximum precamber that could be initially applied with eccentric tensioning was limited by meeting the deflection standards. An efficient way to avoid this limitation in the pretensioning force is to apply a variable tensioning force that generates a counterbalance effect relative to the applied forces. With this goal in mind, the authors developed the SsSC (Self-stressing System) [34, 35].

4.3. Influence of Pretensioning on the Bending Stiffness. Increasing the bending strength of a specimen is not usually the fundamental objective of pretensioning because the dimensions of simply supported specimens are not typically determined by the ultimate limit states but by the service limit states.

The first positive effect provided by pretensioning is to impart a precamber to a specimen. In this way, the deflections caused by permanent actions are offset, helping to meet the service restrictions imposed by appearance considerations. Nevertheless, a precamber can be easily imparted in laminated timber during its manufacturing process. Therefore, pretensioning is not necessary if offsetting the deflections caused by permanent loads is the only goal. The other two in-service deflection conditions that must be satisfied are to ensure the integrity of the construction elements and user comfort. The essential parameter for fulfilling both requirements is the bending stiffness of the element; this aspect is especially relevant for high live loads.

The stiffness of the pretensioned specimens, with both Picea abies and Quercus robur webs, was clearly inferior to that of the nontensioned specimens, as shown in Figures 7 and 8 . Table 5 shows the midpoint displacement values for a total load of $28 \mathrm{kN}$ (2 loads of $14 \mathrm{kN}$ applied at one-third and two-thirds of the span length, which are equivalent in deflection to a uniform distributed load of $7 \mathrm{kN} / \mathrm{m}^{2}$ ). The average displacement value for the specimens with Picea abies webs was 64.91 for the pretensioned specimens and $58.18 \mathrm{~mm}$ for the nontensioned specimens, representing an $11.6 \%$ increase in deflection. In the case of Quercus robur, the average 
displacement was $63.15 \mathrm{~mm}$ for the pretensioned specimens and 54.54 for the nontensioned specimens; thus, pretensioning increased the deflection by $15.8 \%$. Thus, compared to the equivalent nontensioned specimens, the pretensioned specimens with unbonded tendons presented an effective loss in the stiffness, which was attributed to several factors.

The first factor that could have influenced the obtained deflection results is the use of different plate configurations for the flange-web joint of the two species. The distribution of these connection plates was determined to prevent failure at the joint, which would distort the intended analysis. According to the previous joint design, such failure did not occur; therefore, possible slip or failure was not a determining factor in comparing the results. Finally, the pretensioned specimens experienced a higher deflection than the nontensioned specimens, despite the pretensioned specimens having more connection plates in the flange-web joint.

The second factor that could explain the obtained deflection results is the lower moment of inertia in the pretensioned section because of the groove for the tendon. The groove, as mentioned previously, was vertically oversized to allow for other tensioning configurations. In the specimens with the Picea abies webs, the decrease in the bending stiffness (EI) of the homogenized section was $7.6 \%$. The precamber of the nontensioned specimens measured from the tests was $58.18 \mathrm{~mm}$, so the decrease in the stiffness caused by the groove could theoretically improve that value to a maximum of $62.60 \mathrm{~mm}$. However, the total displacement obtained in the pretensioned specimen was $64.91 \mathrm{~mm}$, representing an additional increase of $3.7 \%$.

In the specimens with the Quercus robur webs, the decrease in the bending stiffness of the homogenized section, calculated with a modulus of elasticity of $11,910 \mathrm{MPa}$, was $7.4 \%$. However, that loss did not correspond to the clear higher displacements that were measured in the tests, indicating a greater decrease in stiffness. Preliminary tests to determine the modulus of elasticity were conducted using the same webs that were used to make the nontensioned T-section specimens. The average modulus of elasticity was $11,910 \mathrm{MPa}$ in the Quercus robur web and 10,875 MPa in the Picea abies web. Surprisingly, the pretensioning force needed to obtain a precamber of $18 \mathrm{~mm}$ was lower in the specimens with the Quercus robur webs $(109.72 \mathrm{kN})$ than in the specimens with the Picea abies webs $(114.32 \mathrm{kN})$. This result can be explained by considering that the timber of the webs in the pretensioned specimen had a lower modulus of elasticity. Given that we know the moment of inertia, tensioning force, and precamber for each of the F2/OAK specimens, we obtained an average modulus of elasticity of $10,090 \mathrm{MPa}$. As a result, a $16.49 \%$ decrease in stiffness was generated by the groove combined with the reduction in the modulus of elasticity $E_{m}$ (from 11,910 to $10,090 \mathrm{MPa}$ ). This decrease in the stiffness increased the average precamber value from $54.54 \mathrm{~mm}$, obtained for the solid specimen, to $63.53 \mathrm{~mm}$ in the specimen with the groove. This value is slightly higher than that obtained from the tests $(63.15 \mathrm{~mm}$, as shown in Table 8).

Finally, the third factor that explains the obtained displacement results was attributed to the differences between the modulus of the compressive modulus of elasticity $\left(E_{c, 0}\right)$ and the tensile modulus of elasticity $\left(E_{t, 0}\right)$ parallel to the grain. The pretensioning of the section increased the compressive stresses and consequently increased the compression area of the section. These are, the normal bending stresses that originated from the eccentric pretensioning and external force, combined with the normal compressive stresses due to pretensioning, led to a displacement in the neutral fiber that increased the compression area. Depending on the relative values of the tensile modulus of elasticity and the compressive modulus of elasticity, the increase in the compression section led to a slight decrease (if $E_{c, 0}<E_{t, 0}$ ) or increase (if $E_{c, 0}>E_{t, 0}$ ) in the stiffness.

To verify the proposed theory, an FEM analysis for solid specimens (types F1/PIC and F1/OAK) and specimens with grooves (types F2/PIC and F2/OAK) was conducted, considering both nontensioned and pretensioned specimens.

Three-dimensional models of hexahedral finite elements with 8 nodes containing 24 degrees of freedom (DOFs) were generated. The contact between the elements accounted for the possibility of dynamic behavior from flexible and/or rigid components, with kinematic restrictions on relative movement (displacement and rotation) between the nodes that formed the connection.

Two cases were assumed for the material properties. In the first case, the global modulus of elasticity was considered. In the second case, a bimodulus material was used to define not only the different elastic moduli for both compression and tension but also the different stress-strain curves for compression and tension.

The global bending modulus of elasticity $\left(E_{0 \text {,mean,test }}\right)$ and compression modulus of elasticity parallel to the grain $\left(E_{c, 0 \text {,test }}\right)$ were determined in previous tests (Table 4$)$. Using (4) [36], which is well known for determining the virtual modulus of elasticity $\left(E_{m}\right)$ in softwood, we estimated the tensile modulus of elasticity parallel to the grain $\left(E_{t, 0}\right)$, using the global modulus obtained from the tests $\left(E_{0, \text { mean,test }}\right)$ as the virtual modulus $\left(E_{m}\right)$ :

$$
E_{m}=\frac{4 \cdot E_{t, 0} \cdot E_{c, 0}}{\left(\sqrt{E_{t, 0}}+\sqrt{E_{c, 0}}\right)^{2}} .
$$

Table 8 shows the average displacement values obtained from the experimental tests and those obtained from the numerical analysis. For the pretensioned specimens, the precamber generated by the pretensioning plus the midpoint displacement is noted in parentheses in this table.

The numerical analysis conducted using the virtual modulus of elasticity $\left(E_{m}\right)$ and the bimodulus $\left(E_{c, 0}\right.$ and $\left.E_{t, 0}\right)$ led to interesting conclusions. In the case of the nontensioned specimens, for both the solid section and the section with a groove in the web, the analysis results using the bimodulus showed a high correlation with the results obtained using the virtual modulus of elasticity. This correlation was very similar for the specimens with Picea abies webs and was slightly lower for the specimens with Quercus robur webs; hence, we recommend checking (4) when using it for hardwood. In contrast, in the case of the pretensioned specimens, the results obtained using the bimodulus were 
TABLE 8: Displacement at the midpoint of the span for two point loads of $14 \mathrm{kN}$ applied at one-third and two-thirds of the span.

\begin{tabular}{|c|c|c|c|c|c|c|c|}
\hline \multirow{2}{*}{ Type } & \multirow{2}{*}{$\begin{array}{l}\text { Pretensioning } \\
\text { force }(\mathrm{kN})\end{array}$} & \multirow{2}{*}{$\begin{array}{c}\text { Displacement experimental } \\
\text { test }(\mathrm{mm})\end{array}$} & \multicolumn{3}{|c|}{$\begin{array}{c}\text { Modulus of } \\
\text { elasticity }(\mathrm{MPa})\end{array}$} & \multicolumn{2}{|c|}{ Displacement FEM (mm) } \\
\hline & & & $E_{m}$ & $E_{c, 0}$ & $E_{t .0}$ & $\begin{array}{l}\text { With global modulus of } \\
\text { elasticity } E_{m}\end{array}$ & $\begin{array}{l}\text { With bimodulus } \\
E_{c, 0} \text { and } E_{t, 0}\end{array}$ \\
\hline F1/PIC & - & 58.18 & 10,875 & 10,326 & 11,470 & 58.98 & 58.95 \\
\hline $\mathrm{F} 2 / \mathrm{PIC}$ & $\overline{114.32}$ & $64.91(18.00+46.91)$ & $\begin{array}{l}10,875 \\
10,875\end{array}$ & $\begin{array}{l}10,326 \\
10,326\end{array}$ & $\begin{array}{l}11,470 \\
11,470\end{array}$ & $\begin{array}{c}63.56 \\
63.48(17.27+46.21)\end{array}$ & $\begin{array}{c}63.51 \\
65.64(18.26+47.38)\end{array}$ \\
\hline F1/OAK & - & 54.54 & 11,910 & 12,267 & 11,570 & 55.25 & 54.81 \\
\hline F2/OAK & - & $63.15(18.00+45.15)$ & $\begin{array}{l}10,090 \\
10,090\end{array}$ & $\begin{array}{l}10,390 \\
10,390 \\
\end{array}$ & $\begin{array}{l}9800 \\
9800\end{array}$ & $\begin{array}{c}66.47 \\
64.77(17.22+47.55) \\
\end{array}$ & $\begin{array}{c}65.25 \\
63.67(17.38+46.29) \\
\end{array}$ \\
\hline
\end{tabular}

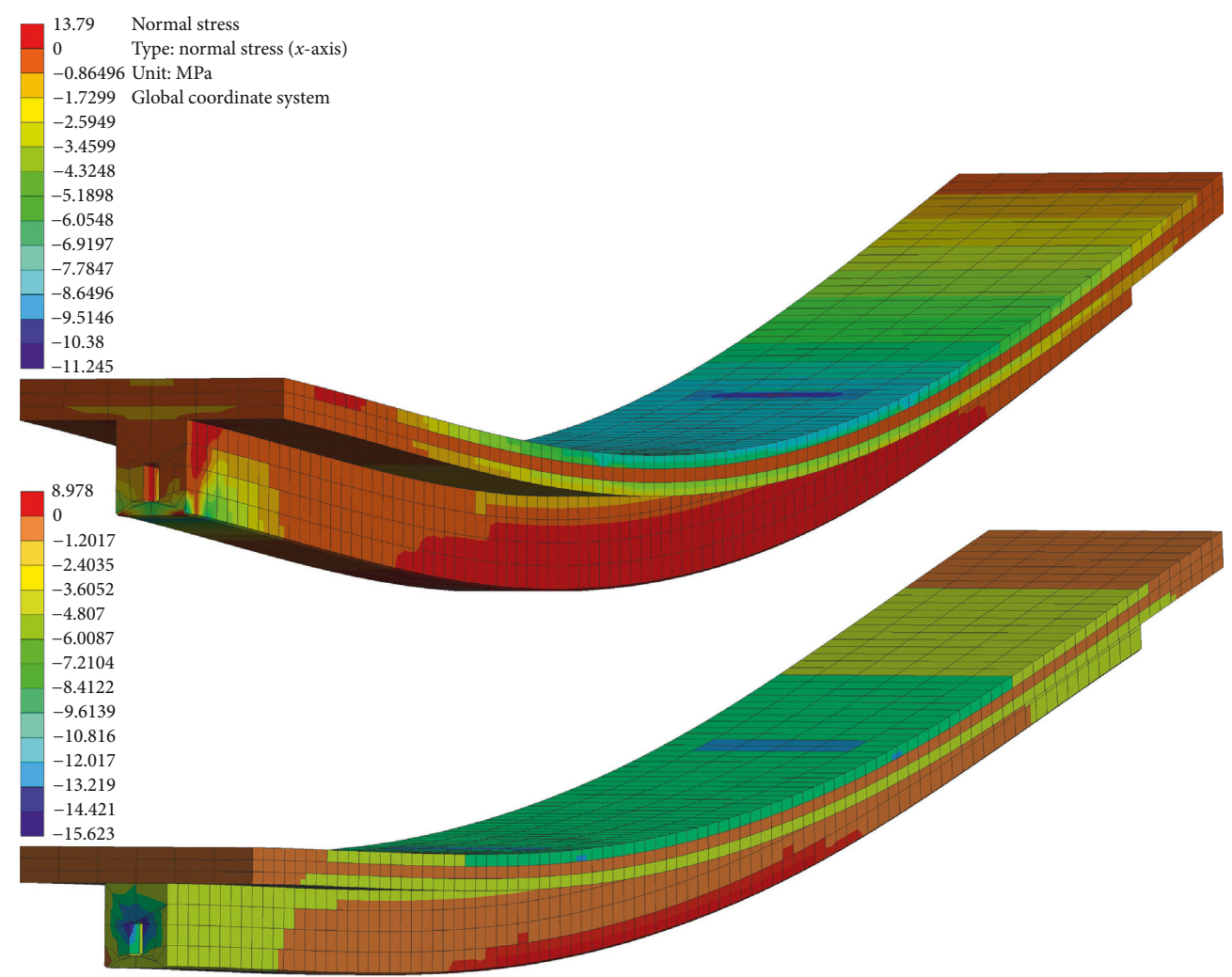

Figure 13: Finite element model. Visualization of the increase of the compressed zone in pieces of T-section with Picea abies webs: pretensioned (bottom) and nonpretensioned (top).

clearly closer to the experimental results than were the results from the analysis using the virtual modulus. The displacement of the pretensioned specimen with Picea abies webs obtained from the numerical model $(65.64 \mathrm{~mm})$ was $11.3 \%$ higher than that of the nontensioned solid specimen $(58.95 \mathrm{~mm})$. In the experimental tests, this increase was $11.6 \%(64.91 \mathrm{~mm}$ for the pretensioned specimen and $58.18 \mathrm{~mm}$ for the nontensioned specimen). In the specimens with Quercus robur webs, the displacement in the numerical model increased by $16.2 \%$, which was practically the same as the increase obtained from the tests $(15.8 \%)$. These results confirm that the variations in the stiffness experienced by the specimens under tension were a consequence of the significant increase in the compression area of the section (Figure 13). To help visualize the pretensioning phenomenon, the areas with tensile stress, regardless of the magnitude, are shown in red in Figure 13.

The results presented here significantly differ from those obtained by McConnell et al. [26]. In our experimental tests, the pretensioned Picea abies specimens showed an $11.6 \%$ higher deflection than the nontensioned specimens. This $11.6 \%$ increase was reduced to $3.7 \%$ after disregarding the loss of inertia due to the groove where the tendon was placed. Conversely, in the tests conducted by McConnell et al. [26], the pretensioning reduced the deflection by $8.1 \%$. This disagreement was attributed to the interactions of several factors. First, the tendon was placed much closer to the edge of the specimen $(22.5 \mathrm{~mm}$ instead of $105 \mathrm{~mm})$. Second, the 
sizes of the tested specimens were different (sections of $45 \times 145 \mathrm{~mm}$ with a $3 \mathrm{~m}$ span facing the T-sections with a $300 \mathrm{~mm}$ depth and $9 \mathrm{~m}$ span). Third, there were possible differences in the relation between the compressive and tensile moduli of elasticity parallel to the grain of the timber used in the tests. The above-mentioned circumstances could generate a greater rotational restraint at the edges of the specimens to reduce the deflection. Moreover, the benefit of pretensioning indicated by McConnell's experiments was also small.

\section{Conclusions}

Using Quercus robur instead of the usual Picea abies for laminating the webs of T-section specimens led to a $41.2 \%$ increase in the bending resistance and a 5.6\% increase in stiffness. Given that the dimensions of simply supported specimens with a medium or long span are normally determined by deflection limitations, Quercus robur is generally not used due to its high cost and small benefit. The 5.6\% increase in stiffness obtained in the tests could be achieved by increasing the depth of the Picea abies web by only $2.7 \%$.

Pretensioning the T-sections increased the bending strength by $24.5 \%$ for the specimens with Picea abies webs. The average failure load of the T-sections with Quercus robur webs was lower in pretensioned specimens than that in the nontensioned specimens, even though the difference was only $2.6 \%$.

The bending stiffness is a fundamental property for dimensioning simply supported specimens, and pretensioning slightly varied the stiffness of the section because of the increased compression area. We proved that such stiffness variations depend on the relation between the compressive and tensile moduli of elasticity parallel to the grain. In the analyzed cases, we found a 3.7\% decrease in the stiffness of the specimens with Picea abies webs and a very slight increase in the specimens with Quercus robur webs (discounting the reduction due to the groove).

Due to the number of tested specimens and the use of different configurations for the flange-web joints with gluedperforated steel plates, we advise conducting another experimental test series to confirm the obtained conclusions.

\section{Conflicts of Interest}

The authors declare that there are no conflicts of interest.

\section{Acknowledgments}

This research is part of the research project "Highperformance prefabricated systems made of prestressed laminated wood without adhered tendons" financed by the Spanish Ministry of Economy and Finance and the European Regional Development Fund (ERDF).

\section{References}

[1] A. Borri and M. Corradi, "Strengthening of timber beams with high strength steel cords," Composites: Part B, vol. 42, no. 6, pp. 1480-1491, 2011.
[2] J. Soriano, B. P. Pellis, and N. T. Mascia, "Mechanical performance of glued-laminated timber beams symmetrically reinforced with steel bars," Composite Structures, vol. 150, pp. 200-207, 2016.

[3] H. Yang, W. Liu, W. Lu, S. Zhu, and Q. Geng, "Flexural behavior of FRP and steel reinforced glulam beams: experimental and theoretical evaluation," Construction and Building Materials, vol. 106, pp. 550-563, 2016.

[4] N. Plevris and T. C. Triantafillou, "FRP-Reinforced wood as structural material," Journal of Materials in Civil Engineering, vol. 4, no. 3, pp. 300-317, 1992.

[5] N. Plevris and T. C. Triantafillou, "Creep behavior of FRPreinforced wood members," Journal of Structural Engineering, vol. 121, no. 2, pp. 174-186, 1995.

[6] T. C. Triantafillou, "Shear reinforcement of wood using FRP materials," Journal of Materials in Civil Engineering, vol. 9, no. 2, pp. 65-69, 1997.

[7] A. Yusof and A. L. Saleh, "Flexural strengthening of timber beams using glass fibre reinforced polymer," Electronic Journal of Structural Engineering, vol. 10, pp. 45-56, 2010.

[8] G. M. Raftery and A. M. Harte, "Low-grade glued laminated timber reinforced with FRP plate," Composites Part B, vol. 42, no. 4, pp. 724-735, 2011.

[9] G. M. Raftery and A. M. Harte, "Nonlinear numerical modelling of FRP reinforced glued laminated," Composites Part B, vol. 52, pp. 40-50, 2013.

[10] P. De La Rosa García, A. C. Escamilla, and M. N. González García, "Bending reinforcement of timber beams with composite carbon fiber and basalt fiber materials," Composites Part B, vol. 55, pp. 528-536, 2013.

[11] A. D’Ambrisi, F. Focacci, and R. Luciano, "Experimental investigation on flexural behavior of timber beams repaired with CFRP plates," Composite Structures, vol. 108, pp. 720728, 2013.

[12] P. De La Rosa García, A. C. Escamilla, and M. N. González García, "Analysis of the flexural stiffness of timber beams reinforced with carbon and basalt composite materials," Composites Part B, vol. 86, pp. 152-159, 2016.

[13] I. Glisovic, B. Stevanovic, and M. Todorovic, "Flexural reinforcement of glulam beams with CGRP plates," Materials and Structures, vol. 49, no. 7, pp. 2841-2855, 2016.

[14] T. Smith, F. C. Ponzo, A. Cesare et al., "Post-tensioned glulam beam-column joints with advanced damping systems: testing and numerical analysis," Journal of Earthquake Engineering, vol. 18, no. 1, pp. 147-167, 2014.

[15] F. Wanninger and A. Frangi, "Experimental and analytical analysis of a post-tensioned timber connection under gravity loads," Engineering Structures, vol. 70, pp. 117-129, 2014.

[16] B. Bohannan, "Prestressed wood laminated beams," Forest Products Journal, vol. 12, no. 12, pp. 596-602, 1962.

[17] T. C. Triantafillou and N. Deskovic, "Prestressed FRP sheets as external reinforcement of wood members," Journal of Structural Engineering, vol. 118, no. 5, pp. 1270-1284, 1992.

[18] C. W. Dolan, T. L. Galloway, and A. Tsunemori, "Prestressed glued laminated timber beam-Pilot study," Journal of Composites for Construction, vol. 1, no. 1, pp. 10-16, 1997.

[19] A. Buchanan, A. Palermo, D. Carradine, and S. Pampanin, "Post-tensioned timber frame buildings," Structural Engineer, vol. 89, no. 17, pp. 24-30, 2011.

[20] M. Davies and M. Fragiacomo, "Long-term behavior of prestressed LVL members. I: experimental tests," Journal of Structural Engineering, vol. 137, no. 12, pp. 1553-1561, 2011. 
[21] V. De Luca and C. Marano, "Prestressed glulam timbers reinforced with steel bars," Construction and Building Materials, vol. 30, pp. 206-217, 2012.

[22] J. Negrâo, "Prestressing systems for timber beams," in Proceedings of World Conference on Timber Engineering WCTE-12, vol. 1, pp. 252-261, Auckland, New Zealand, July 2012.

[23] W. Van Beerschoten, A. Palermo, D. Carradine, and S. Pampanin, "Design procedure for long-span post-tensioned timber frames under gravity loading," in Proceedings of World Conference on Timber Engineering WCTE-12, vol. 1, pp. 354-361, Auckland, New Zealand, July 2012.

[24] F. Wanninger, A. Frangi, and M. Fragiacomo, "Long-term behavior of posttensioned timber connections," Journal of Structural Engineering, vol. 141, no. 6, article 04014155, 13 pages, 2015.

[25] T. Smith, F. Sarti, G. Granello et al., "Long-term dynamic characteristics of Pres-Lam structures," in Proceedings of World Conference on Timber Engineering WCTE 2016, Vienna, Austria, August 2016.

[26] E. McConnell, D. McPolin, and S. Taylor, "Post-tensioning of glulam timber with steel tendons," Construction and Building Materials, vol. 73, pp. 426-433, 2014.

[27] EN 14080, Timber Structures. Glued Laminated Timber and Glued Solid Timber, Requirements, European Committee for Standardization (CEN), Brussels, Belgium, 2013.

[28] ETA 13/0642, VIGAM-Glued Laminated Timber of Oak, European Technical Assesment, Brussels, Belgium, 2013.

[29] ETA 14/0349, CLT-Cross Laminated Timber, European Technical Assesment, Brussels, Belgium, 2014.

[30] EN 338, Structural Timber. Strength Classes, European Committee for Standardization (CEN), Brussels, Belgium, 2009.

[31] prEN 10138-4, Prestressing Steels-Part 4: Bars, European Committee for Standardization (CEN), Brussels, Belgium, 2000.

[32] EN 408, 2010+A1, Timber Structures. Structural Timber and Glued Laminated Timber. Determination of Some Physical and Mechanical Properties, European Committee for Standardization (CEN), Brussels, Belgium, 2012.

[33] ETA 05/0123, Dywidag-System International GmbH, European Technical Assesment, Brussels, Belgium, 2013.

[34] J. Estévez-Cimadevila, D. Otero-Chans, E. Martín-Gutiérrez, and F. Suárez-Riestra, "Self-tensioning system for long-span wooden structural floors," Construction and Building Materials, vol. 102, pp. 852-860, 2016.

[35] D. Otero-Chans, J. Estévez-Cimadevila, E. Martín-Gutiérrez, and J. Pérez-Valcárcel, "Application of a new system of selftensioning to the design of large-span wood floor framings," Journal of Structural Engineering, vol. 142, no. 6, p. 04016012, 2016.

[36] V. Baño, R. Argüelles-Bustillo, R. Regueira, and M. Guaita, "Determination of the stress-strain curve in specimens of Scots pine for numerical simulation of defect free beams," Materiales de Construcción, vol. 62, no. 306, pp. 269-284, 2012. 


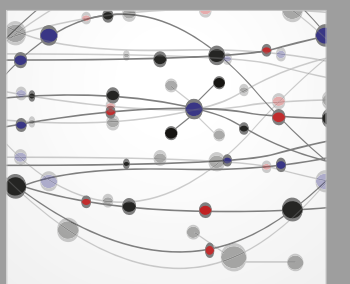

The Scientific World Journal
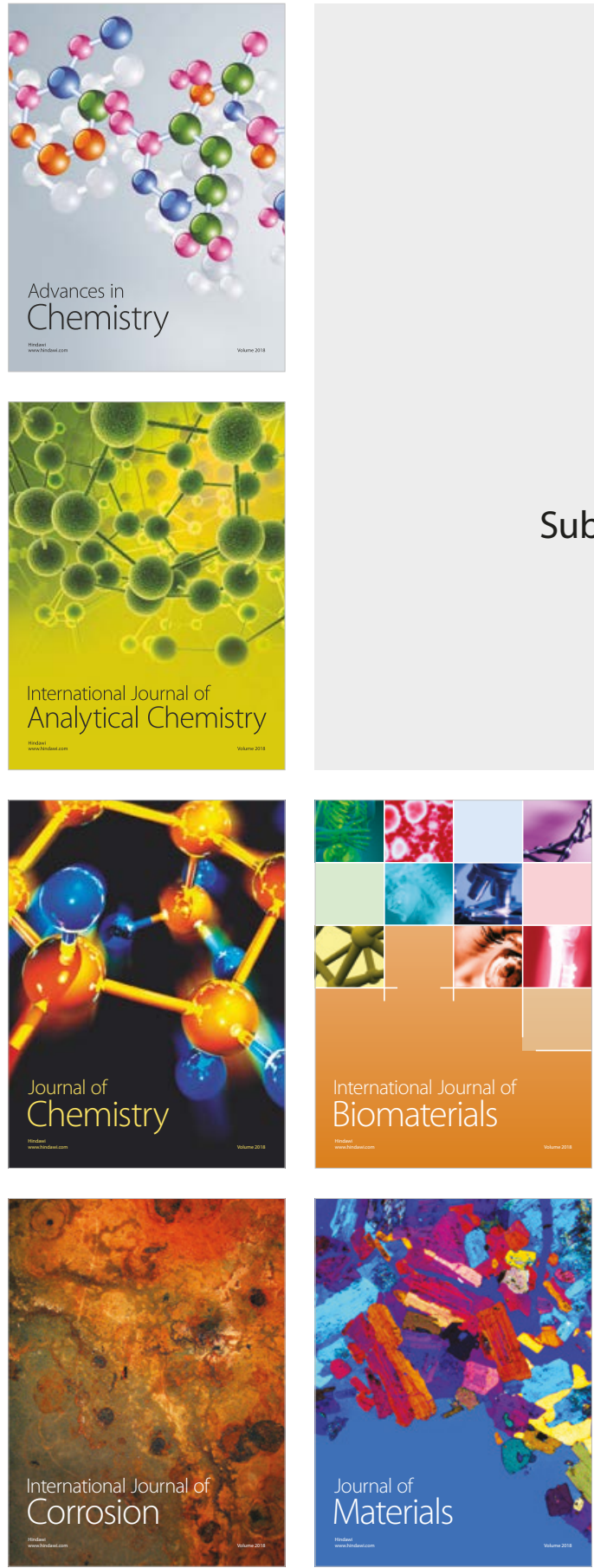

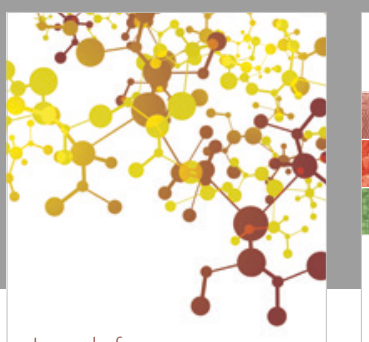

Journal of

Applied Chemistry
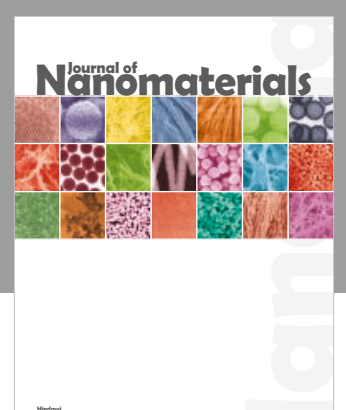

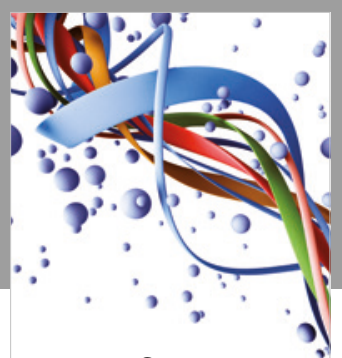

Scientifica

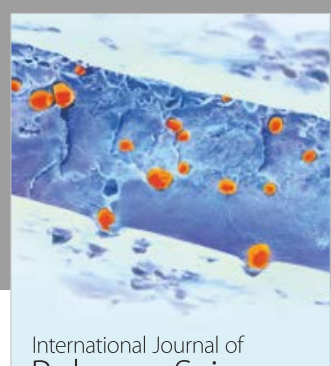

Polymer Science

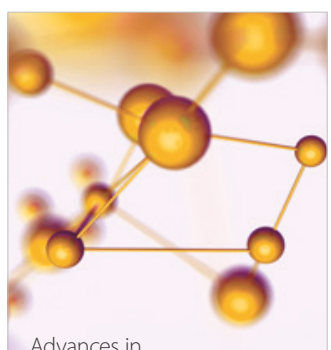

Physical Chemistry
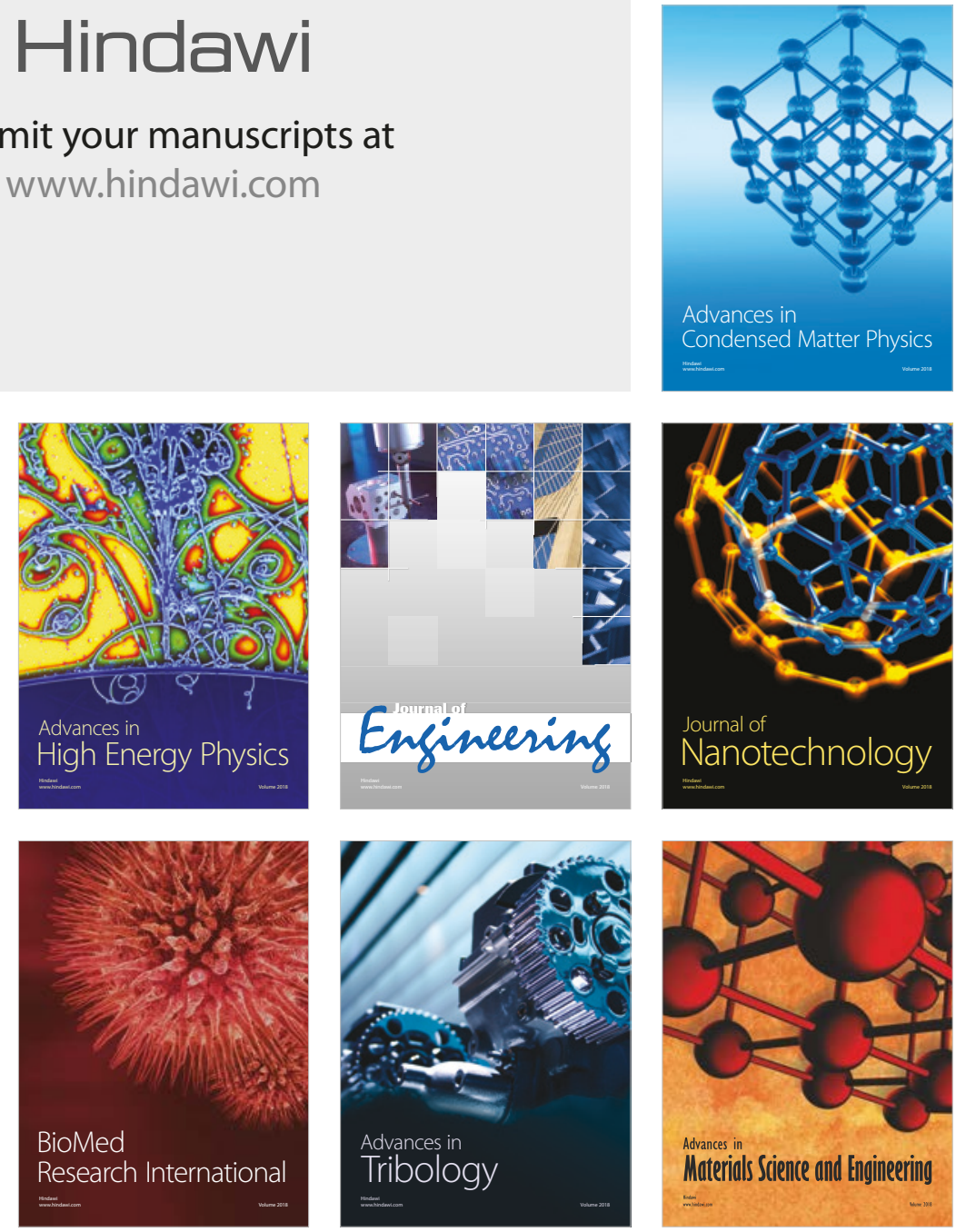